\title{
Speaking the Language of Love: On Whether Chapman's (1992) Claims Stand Up to Empirical Testing
}

\author{
Denise M. Polk* and Nichole Egbert
}

Main Hall, West Chester University, West Chester, PA 19383, USA

\begin{abstract}
This paper explores and tests the claims made by Chapman (1992) in his popular press book, The Five Love Languages: How to Express Heartfelt Commitment to your Mate. One of Chapman's fundamental claims is that couples where partners receive their respective preferred love languages experience higher quality relationships than couples who do not. Couples $(N=83)$ reported their preferences for and tendencies to demonstrate Chapman's five love languages. They also completed measures of relational quality. Descriptive results revealed different potential couple combinations in terms of feeling and giving preferred love languages, and suggest that few couples meet Chapman's criteria for high relational quality. After collapsing couple combinations to reflect matched, mismatched, or partially matched couples (in terms of feeling and giving their love language preferences), a significant result surfaced regarding assessments of relational quality. More specifically, matched and mismatched couples' reports of relational quality exhibited less discrepancy than partially matched couples. Other results from tests of ANOVA and MANOVA provided little empirical support for Chapman's notions of love languages.
\end{abstract}

Keywords: Love languages, relational quality, affection, romantic couples.

\section{INTRODUCTION}

"He sends you flowers when what you really want is time to talk... The problem isn't your love - it's your love language" (Chapman, 1992, back cover). In his best-selling book, "The Five Love Languages: How to Express Heartfelt Commitment to Your Mate," Dr. Gary Chapman promoted a theory that has gained widespread public approval. For example, the government of Singapore and the Chaplain's Office of NATO invited him to speak, and the book has been a perennial New York Times Bestseller, selling over seven million copies (Marriage \& Family Life Consultants). Chapman's main thesis is that there are five emotional love languages (LLs) - ways that people "speak" and understand emotional love. Despite the fact that the number of ways to express love through LLs is essentially limitless, people must learn to "speak" the LL of their partner because relational satisfaction hinges on filling a partner's metaphorical emotional "love tank" (Chapman, 1992).

Academic researchers often criticize popular books as oversimplifying complex ideas, but Chapman's (1992) claims parallel some relational scholarship. For example, Egbert and Polk (2006) found the LLs formed five distinct factors, and they found significant relationships between several relational maintenance factors and LLs. Therefore, one goal of this project is to test the foundation of Chapman's claims through empirical investigation. Specifically, we tested Chapman's thesis that couples where partners tend to give love in ways that aligns with their

*Address correspondence to this author at the Main Hall, West Chester University, West Chester, PA 19383, USA; Tel: 610-436-2658;

Fax: 610-436-3046; Emails: dpolk@wcupa.edu partners' preferred LLs actually enjoy higher quality relationships.

\section{CHAPMAN'S FIVE LOVE LANGUAGES}

Empirical support for Chapman's (1992) book is mixed when compared with communication scholarship. Chapman's (1992) basic claim about the fundamental need for love and affection is well-documented empirically (Floyd, 2006; Floyd, Hesse, \& Haynes, 2007; Schutz, 1958), affecting well-being (Downs \& Javidi, 1990) and affecting different types of relationships (e.g., Floyd \& Morman, 2003; Schrodt, Ledbetter, \& Ohrt, 2007). It also plays a significant role in relational maintenance (Bell \& Healey, 1992) and quality (Floyd \& Morman, 1998). In fact, Floyd (2006) claimed that humans need to be shown they are loved, and other researchers have documented ways people accomplish this expression (Villard \& Whipple, 1976).

Several theories can be used to predict and/or explain affectionate behaviors. For example, Floyd (2006) reviewed theories used to frame studies of affectionate behavior, and included Thibaut and Kelley's (1959) interdependence theory, expectancy violations theory (Burgoon, 1978), and interaction adaptation theory (Burgoon, Dillman, \& Stern, 1993). Floyd's review explained how affection exchange theory (Floyd, 2001) addresses the existing theories' inability to predict or explain affectionate communication.

According to Chapman (1992), no emotional need is more basic than the need for love and affection, and people express love according to five LLs: words of affirmation (encouraging and affectionate messages), quality time (spent together relating or in shared activities), gifts (thoughtful tokens), acts of service (help with tasks), and physical touch 
(hand-holding to sexual intercourse). Although Chapman uses the term "speak," four of these LLs largely are nonverbal; however, despite the word choice, the five LLs include behaviors that fall under the scope of what Floyd and Morman (1998) named a tripartite model of affectionate behavior (verbal, nonverbal, and supportive behaviors).

The first part of Chapman's (1992) thesis is that people tend to have a distinct preference for a specific LL. Chapman claimed that, often, people will instantly know their own LL after hearing it described. Similarly, Hazan and Shaver (1994) successfully tested adult romantic attachment by collapsing scale items into forced-choice items; yet, more recently, researchers advocate using continuous measures (e.g., Feeney, 2008). Employing Egbert and Polk's (2006) validated 20-item Love Language Scale (LLS; four items for each dimension), our first goal was to compare forced-choice measurement with the 20-item scale using continuous scores. Therefore, we asked:

RQ1: Does a relationship exist between a partner's forced-choice feel love language and the means associated with their own feel Love Language Scale subscores?

In the second part of his thesis, Chapman (1992) added that when partners speak each other's primary LL, their need for love will be satisfied, resulting in high relational quality; however, when they do not, their love tank will drain. He suggests that receiving a singular preferred LL is more important for keeping the tank full than receiving a combination of all five. Yet, empirical data from other researchers suggests otherwise. For example, social support literature suggests that support functions differentially and impacts outcomes based on contextual needs (Cutrona \& Suhr, 1990, 1992). Johnson (2001) suggested that the more behaviors practiced, the greater the relational satisfaction, and Leverett (2007) claimed that the relationship between maintenance and satisfaction may be dependent on quantity and quality of behaviors.

According to Chapman (1992), couples often have different LL preferences. This can pose problems because most people automatically give their own preferred LL regardless of their partner's LL preference (Chapman, 1992). Therefore, a key to high relational quality is to recognize a partner's preference and to engage in behaviors that communicate that particular LL. This claim has been supported empirically. For example, Floyd (2006) found that "although affectionate behaviors may carry some inherent positivity, their valence is also determined by the extent to which they are congruent with a recipient's desires" (p. 86). Thus, people may give the LL they prefer to receive, hoping it will be reciprocated. However, Floyd (2006) claimed that people often compensate when they receive affection incongruent with their desires, or they ignore/fail to perceive the behavior as affectionate. Chapman echoed these ideas, claiming that mismatches occur when one partner fails to recognize and respond appropriately to a partner's LL. Floyd (2006) also addressed this issue, arguing that ignoring affection behaviorally often indicates the recipient is uncertain as to how to respond. Of course, if both people desire the same LL, then it is likely that partners tend to reciprocate that LL increasingly over time, leading to higher relational quality. Using Floyd's (2006) language of affectionate behavior, then, Chapman's thesis hinges on the idea that when people's LLs are different, they should compensate for those differences by actively choosing behaviors that reflect the other person's desired LL.

On the other hand, Chapman's (1992) ideas diverge from some scholars about the frequency of affectionate behaviors. For example, Villard and Whipple (1976) contended that people ascribe more value to rarely-used currencies, value frequently used currencies less, and that unused currencies possess no value. Dainton (2000) found that people expect partners to perform all types of relational maintenance behaviors. According to Chapman, however, the frequent expression of a partner's LL is the best contribution to relational quality, and although Chapman agrees that partners must exchange desired LLs over the long term, he does not advance that LLs can be equally valued beyond one (or sometimes two) favorite/s.

Furthermore, people differ regarding their expression and receipt of affectionate communication (Floyd, 2003, 2006; Floyd, et al., 2005). Floyd (2006) outlined a range of optimal tolerance for affection that considers both need and desire, as well as upper and lower thresholds. These thresholds both can be problematic in different ways (Floyd, 2006). This is very different from Chapman's (1992) claim that only the failure to receive one's minimum threshold is problematic. He does not address the possibility that people potentially could receive too much affection. To understand people's tendency to enact the LL behaviors that they prefer to receive rather than the LL behaviors their partner prefers, to receive we ask:

RQ2: Does a relationship exist between a partner's forced-choice feel love language preference with their partner's tendency to give Love Language Scale subscores?

Chapman (1992) argues that the key to relational quality is more than recognizing a partner's LL by learning how to enact behaviors that demonstrate the LL. He maintains that people must consciously prioritize a partner's needs to enhance relational quality, but does not offer empirical evidence for his claims, nor does he discuss situations where both partners receiving their desired LL, only one partner receiving his or her desired LL, or neither receiving desired LLs. This information can be obtained by categorizing each couple based on the LL preferences they report feeling/preferring and giving. Once all the types have been identified, they can be collapsed to represent matches (both report giving each other's preferred LL), partial matches (only one reports giving the other's preferred LL), and mismatches (neither person reports giving their partner's preferred LL). Therefore, the following question provides a basis for exploring these claims:

RQ3: What are the most common couple types given the different potential LL configurations?

Moving forward to examine Chapman's claims about relational satisfaction, evidence from empirical scholarship is largely supportive. Burleson and Denton (1992) predicted that a couple's similarity in social skill impacts marital satisfaction. Burleson, Kunkel, and Birch (1994) found that although similarity in communication did not impact whether people dated each other, it contributed to their relational satisfaction and partner attraction. A basic idea behind interdependence theory (Thibaut \& Kelley, 1959) is 
that as couples become more deeply involved, they become more dependent upon their relationship. This dependence is linked with satisfaction and commitment. More importantly, the greater their satisfaction and commitment, the more likely they are to use pro-relationship behaviors (i.e., relational maintenance) to preserve and maintain that satisfaction and commitment (Rusbult, Olsen, Davis, \& Hannon, 2001).

This is also true of interaction adaptation theory (Burgoon et al., 1993) which posits that people compare their needs, expectations, and desires to the behaviors of conversational partners and reciprocate behaviors that match or are more positive than those needs, expectations, and desires. Floyd and Burgoon (1999) found that people will match increasing affectionate behavior and compensate for decreasing affectionate behavior when they desire and expect affection. They also addressed the outcomes of situations where people desire one thing but expect another. Chapman (1992) really does not address the possibility that although people may desire a particular LL, they might expect their spouse to give a different one (perhaps simply based on past interactions). Instead, he argued that people cannot and do not feel loved if partners do not provide their desired LL, often because the enacted behaviors may not register as affectionate behaviors. However, Dainton's (2000) results support Chapman's claim about the relationship between LLs and satisfaction in that the extent to which expectations about partner maintenance behaviors were met related positively to relational satisfaction. Thus, failing to enact certain behaviors may lead partners to feel unloved. Chapman's theory and interdependence theory suggest that relational quality relates to partners meeting or exceeding expectations of receiving their desired LL; thus, this study explored how matches and mismatches in giving/getting LLs could impact relational quality. Therefore, we asked the following two research questions:

RQ4: Is self-reported relational quality impacted by the degree to which one partner's feel love language preference matches their partner's reported tendency to give love language?

RQ5: Is self-reported relational quality predicted by couple types?

\section{MATERIALS AND METHODOLOGY}

\section{Participants and Procedures}

Couples $(N-86)$ included students enrolled in a speech course at a large Midwestern university who also were in a current romantic relationship of at least two months ( $n-95)$ and their romantic partners $(n-71)$ [ 86 females, 83 males, 3 unreported: ages 18-22 ( $n$ - 148), 23-30 ( $n$ - 11), 30-40 ( $n$ $3)$, over $40(n-2)$, and no age reported $(n-8)]$. Three couples were excluded from the study because at least one partner left a significant number of items blank. Students received course credit for completing this study (some couples involved students for both partners), and the names of non-student partners were put into a gift certificate drawing for their participation. Students and their romantic partners completed the questionnaires under the authors' supervision in a university classroom. Couples arrived together and received questionnaire packets with corresponding codes so partners could be matched up. Participants were predominantly Caucasian ( $n$ - 147): [African American $(n-6)$, Asian American $(n-1), \&$ "other" or unreported $(n-18)]$. Most participants were first or second year students $(n-107)$ : [juniors or seniors $(n-35)$, graduate students $(n-1)$, not in college $(n-16) \&$ unreported $(n-13)]$. A majority of participants reported their marital status as never married ( $n$ - 125): [married, divorced, or widowed $(n-34) \&$ "other" or unreported $(n-13)]$. Relationship length ranged from 2-6 months $(n-39), 6$ months to 2 years $(n-67), 2-5$ years $(n-43)$, over 5 years $(n$ - 15), and unreported $(n-8)$.

\section{Measures}

Love languages. Participants received a forced-choice LL measure. The instructions read: "Please select the statement that best describes you by filling in ONE of the appropriate/corresponding bubbles. It may be hard to choose just ONE answer, but try to figure out which of the following is most important to you... "Participants had five choices of "I feel the most love when my partner\&": (1) physically touches me (i.e., gives a hug, gives a kiss, holds my hand, touches me), (2) helps me out (i.e., running an errand, finishing a chore for me, helping me out, helping to keep things cleaned up), (3) spends quality time with me (i.e., really listening, doing something we both like, engages in quality conversation, spending free time), (4) says encouraging words (i.e., compliments, expresses appreciation for me, gives me credit for something I did, gives me positive comments), or (5) gives me gifts (i.e., a thoughtful birthday gift, a greeting card, a present for no special reason, a gift after being away). These items were collapsed from Egbert and Polk's (2006) 20-item LLS. This method parallels Hazan and Shaver (1987, 1994), who collapsed attachment style scale items into forced-choice items, one for each style.

Later in the questionnaire packet, each participant also completed two versions of the LLS - in one version, participants responded to each item about how they tended to prefer, or feel, love whereas in the other version, they responded about how they tended to give love to their partner. The LLS scale consists of 20-Likert-type items that represent Chapman's (1992) five different LLs (four items for each dimension). Egbert and Polk (2006) reported sufficient reliability and construct validity, demonstrating significant relationships between the LLs and relational maintenance.

The rationale for creating a forced-choice LL and then also having them complete the LLS was to explore the extent to which people can self-identify their LL and the extent to which that preference is reflected in the LLS score when they could rate all five LLs. Although Hazan and Shaver's (1987) method of measuring attachment by selecting a single statement has been established as consistently reliable (e.g., Fuller \& Fincham, 1995; Hazan \& Shaver, 1994; Meyers \& Landsberger, 2002; Weger \& Polcar, 2000; 2002), more recently researchers advocate continuous measures (Cassidy \& Shaver, 2008).

Reliability analyses from the current study suggested the LLS is a reliable measure. Cronbach's alphas ranged from .80 to .85 for participant responses regarding how they feel 
and give love. These numbers are in line with previous reliability (see Egbert \& Polk, 2006). In addition, confirmatory factor analyses (CFAs) using AMOS 20.0 helped test each scale's validity. This also helped to identify any potentially problematic items that might compound any reduction to the goodness of fit of the overall model. Results of the CFAs suggested a good fit for each of the five LL dimensions: words $\left(\chi^{2}-34.37 ; d f-19 ; p<.05\right.$; GFI - .95; RMSEA - .07), time $\left(\chi^{2}-50.61 ; d f-19 ; p<.001\right.$; GFI - .93; RMSEA - .09), gifts $\left(\chi^{2}-55.99 ; d f-19 ; p<.001\right.$; GFI - .93; RMSEA - .09), touch $\left(\chi^{2}-20.35 ; d f-19 ; p-.37\right.$; GFI - .97; RMSEA - .07), and acts $\left(\chi^{2}-36.67 ; d f-19 ; p<.01\right.$; GFI .95 ; RMSEA - .07). RMSEA fits up to .08 may reasonably account for error (Browne \& Cudeck, 1993) and MacCullum, Browne, and Sugawara (1996) claimed fits of .08 to .10 represent mediocre fits. In addition, traditionally an omnibus cut-off point of 0.90 has been recommended for the GFI; however, when sample sizes are low a higher value of 0.95 is preferred (Miles \& Shevlin, 1998). To avoid accepting misspecified models, $\mathrm{Hu}$ and Bentler (1999) recommended not accepting values under 0.90 . Furthermore, our sample was small (i.e., defined as less than 200. Therefore, where small samples are used, the chi-square may not discriminate between good fitting models and poor fitting models (Kenny \& McCoach, 2003). Researchers have sought alternative indices to assess model fit. One such alternative is Wheaton, Muthen, Alwin, and Summer's (1977) relative/normed chi-square ( $\chi 2 /$ df). Although no consensus exists about an acceptable ratio for this statistic (Bollen, 1989), recommendations range from as high as 5.0 (Mueller, 1996; Wheaton et al., 1977) to below 3.00 (Mueller, 1996). Taken together, although the results of the CFA do not meet all the criteria of the most stringent guidelines, they certainly do fall within ranges considered acceptable to good.

Quality of relationships inventory (QRI). Participants completed the three-dimensional (depth, support, and conflict), 25-item, Likert-type QRI $(1=$ not at all to $5=$ very much; Pierce, 1994). The QRI is a valid and reliable indicator of relational quality, consistently highly correlated to observers' ratings of social behavior (Pierce, 1994). In the current study, reliability of the subscales (Cronbach alphas) was acceptable: depth $=.76$ (it contains the fewest items, and deleting any items further reduced the alpha level), support = .81 , and conflict $=.87$. These numbers are similar to Verhofstadt, Buysse, Rosseel, and Peene, (2006) who tested the psychometric properties of the QRI, separating scores by gender. Subscale alphas ranged from .79-.88. CFA results indicated each dimension fit the data (support: $\chi^{2}-17.66, d f$ $14, p-.13$, RMSEA - .05, CFI - .97, IFI - .97; depth: $\chi^{2}-$ $16.17, d f-9, p-.06$, RMSEA - .07, CFI - .97, IFI - .97; conflict $\chi^{2}-107.43, d f-54, p-.00$, RMSEA - .08, CFI - .92, IFI - .92). As with the LLS, these numbers do not reflect an ideal fit, but they suggest what many researchers consider acceptable levels of fit.

Among male participants, frequencies for forced-choice LL are as follows: (a) touch feel/give $n-39,34$; (b) acts feel/give $n-4,3$; (c) time feel/give $n$ - 31, 40; (d) words $n$ 6, 5; and (e) gifts $n-5$, 5. In addition, of the female participants, self-reports of each of the types of LL are as follows for feel/give: (a) touch $n-31,30$; (b) acts $n-3,3$; (c) time $n-33,35$; (d) words $n-14,12$; and (e) gifts $n-2,3$.
Undistinguished gender couples (where one or both partners did not identify gender $(n-3)$ were not excluded from the analyses.

\section{RESULTS}

To address the first question about the forced-choice option as compared with LLS scores, we ran five separate one-way ANOVAs for each partner using the participant's forced-choice feel LL and the mean scores of their own feel LLS responses for the five dimensions. Not only were there no significant differences (see Table 1), but the forcedchoice LL for each individual did not always correspond with the highest mean score of the five LLS dimensions. Thus, stating a preference for "touch" in the forced-choice question did not significantly correspond with higher scores in the touch subscale of the LLS, as compared with those who stated a preference for one of the other categories. Participants' forced-choice feel LL matched only six of the highest means of the LLS dimensions ( 4 of 5 for men and 2 of 5 for women). For men, the LLS mean score for acts was $(M-17.25, s d-2.22)$, for gifts was $(M-19.33, s d-1.15)$, for time was $(M-17.03$, sd - 2.52), and for words was $(M-$ $17.67, s d-1.75)$. The highest mean for the forced-choice LL as compared with the LLS means with forced-choice touch actually was time $(M-18.38, s d-2.04)$. For women, forcedchoice answers only corresponded with two of the means for the LLS dimensions: gifts $(M-19.00, s d-1.41)$ and touch $(M-18.71, s d-1.85)$.

As an additional way to address the first question about the feel forced-choice option as compared with feel LLS scores, we conducted a mixed-model MANOVA with forced-choice $f e e l \mathrm{LL}$ as the between subjects factor, and the feel LLS responses for each of the five dimensions as the dependent variables. To account for within-dyad variance, we treated role in dyad (male or female) as a within-subjects factor. Because role in dyad was input as a within-subjects factor, we could not also run it as a predictor, betweensubjects factor. Therefore, the results reported represent all participants and are not broken down by into male and female. Forced-choice feel LL was not significantly related to scores on the five feel LLS dimensions: words $F(4,160)$ $.49, p$-ns, time $F(4,160)-.36, p$ - $n s$, gift $F(4,160)-.48, p$-ns, acts $F(4,160)-.51, p-n s$, and touch $F(4,160)-.31, p-n s$. Means and standard deviations are reported in Table 2. Thus, stating a preference for "touch" in the forced-choice question did not significantly correspond with higher scores in the touch subscale of the LLS, as compared with those who stated a preference for another category.

Similarly, to address the second question about the extent to which partners' reports of the LLs they tend to give compared with their partner's self- identified feel LL, we conducted another set of five one-way ANOVAs. Again, no significant differences occurred for individuals (see Table 3). Descriptively as a group, males' forced-choice reports corresponded with the highest means for the LLS only on the acts dimension $(M-18.33$, sd - 2.89). For females, only forced-choice words $(M-18.33, s d-2.08)$ and gifts $(M-$ $17.33, s d-2.52)$ corresponded with the highest means for the LLS dimensions.

As an additional way to address the second question about the extent to which partners' reports of the LLs they 
Table 1. One-Way ANOVAs Comparing Partners' Forced-Choice Feel Love Language Preferences with their Own Love Language Scale Subscores

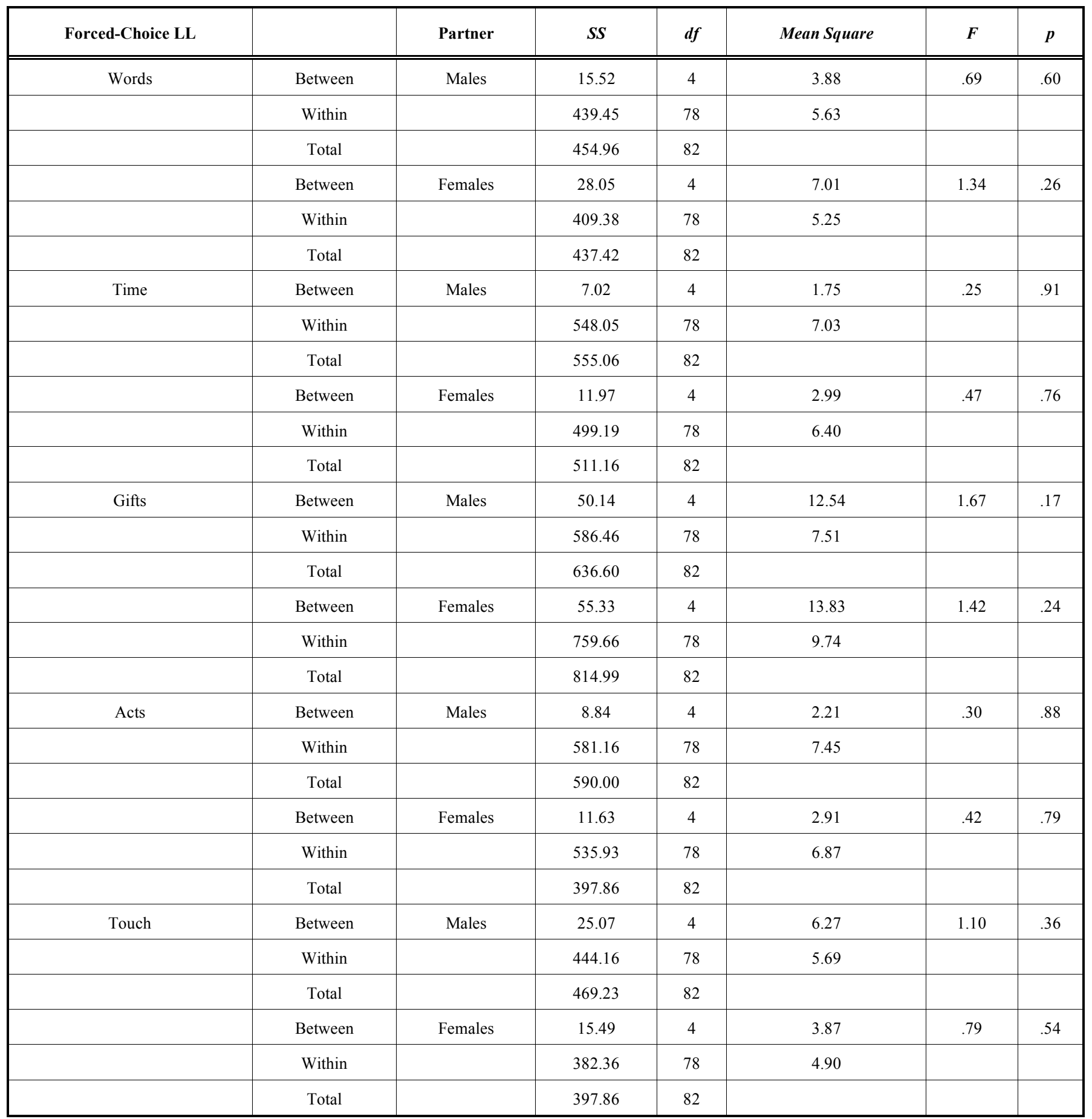

tend to give compared with their partner's feel LL, we conducted another mixed-model MANOVA with forcedchoice feel LL as the between-subjects factor, and the partner give LLS responses for each of the five dimensions as the dependent variables. To account for within-dyad variance, we treated role in dyad (male or female) as a within-subjects factor.

Again, because role in dyad was input as a withinsubjects factor, we could not also run it as a predictor, between-subjects factor. Therefore, the results represent all participants and are not broken down by sex. Forced-choice feel LL was not significantly related to partner give scores on the five LLS dimensions: words $F(4,160)-1.43, p$ - $n s$, time $F(4,160)-.54, p-n s$, gift $F(4,160)-.07, p$-ns, acts $F(4$, $160)-.40, p-n s$, and touch $F(4,160)-1.02, p-n s$. Means and standard deviations are reported in Table 4.

To address the third research question about the potential couple types, first it was necessary to record all the different combinations of couples possible with regard to giving and feeling LLs. For the purpose of this study, we set parameters 
for couple types based on the forced-choice LL the dyadic partners reported feeling and giving, resulting in 12 different types of couples (see Table $\mathbf{5}$ for couple types, frequencies, and examples). Then we collapsed those 12 types down into 3 couple types based on whether the partners matched on giving one another's felt LL, whether they were partly matched (one received his/her felt LL but the other did not), or whether they were mismatched (both partners gave a different LL than their partner's felt LL). Couple types 1 and 12 (see Table 5) represent matches-- the couples Chapman (1992) claimed experience the highest relational quality (although no couple actually surfaced as Type 12). Couple types $3,4,10$, and 11 involve partial matches, and types 2, 5, $6,7,8$, and 9 involve neither partner receiving his/her preferred LL. The most frequently occurring couple type (Type 2, $n$ - 39) represented a mismatch. The within-subject LL consistency between a partner's feel preference and what that partner gives also is worth reporting. For male participants, 68 reported a match, whereas 15 reported a partial match or mismatch. For female participants, 72 reported a match as compared with 11 who reported a partial match or mismatch.

Table 2. Means and Standard Deviations from Mixed-Model MANOVA of Forced-Choice Feel Love Language Preferences with Participants' Own Love Language Scale Subscores

\begin{tabular}{|c|c|c|}
\hline LL Item & Mean & SD \\
\hline \hline Words & 17.27 & 2.33 \\
\hline Time & 17.08 & 2.55 \\
\hline Gifts & 16.25 & 2.99 \\
\hline Acts & 15.99 & 2.66 \\
\hline Touch & 18.12 & 2.30 \\
\hline
\end{tabular}

Investigating the fourth research question involved testing Chapman's prediction that couples who give and receive one another's preferred LL experience enhanced relational quality. We were interested in these collapsed couple types -- whether couples were matched, partially matched, or mismatched with their felt LL preferences and tendencies to give LLs as opposed to whether specific differences in the LL combinations contribute differently to relational quality. Therefore, we used the collapsed couple types of: match (both partners gave and received preferred LLs; $n=22$ ), partial match (one partner received his/her preferred LL, but the other did not; $n=13$ ), and mismatch (neither partner received his/her preferred LL; $n=48$ ). See Table 6. Then, we conducted a one-way ANOVA. Results yielded a significant difference for couple combination on relational quality discrepancy $\left(\mathrm{F}(2,80)=5.92, \mathrm{p}<.005, \eta^{2}\right.$ $=0.13$ ). A Tukey Post Hoc analysis revealed that matched and mismatched couples report greater consistency (less discrepancy) than partially matched couples in assessments of quality. No difference surfaced between matched and mismatched couples, but both were different than partially matched couples (partial and match $=11.36$, partial and mismatch $=10.25$, match and mismatch $=1.11(p<.05$ with unequal cell means, not weighted).
For our final question, we wanted to explore the reports of relational quality (summed QRIs that included both partners) as to whether it could be predicted by collapsed couple type (matched, partially matched, or mismatched couples). We conducted a one-way ANOVA, but the result was not significant $(\mathrm{F}(2,80)-0.70, p-.50)$. To understand more, we examined the total individual relational quality score for each member of each couple. Then, we placed each partner into a low or high quality category and compared whether the couple matched on having high scores, low scores, or mismatched scores (one low score and one high score). We then ran a crosstabs analysis. The result was not significant. $\chi^{2}(4, N-83)-1.84, p-.76$ (see Table 7).

\section{DISCUSSION}

The results of this study extend Chapman's (1992) thesis in a few key ways. First, this study tested the construct validity of Egbert and Polk's (2006) LLS. The forced-choice items were based the LLS, so it provided a different way for testing the predictive ability of the LLS. Because Egbert and Polk only tested how one's partner tends to feel loved, this study extends the validity of the LL items because it examined both partners, providing a better snapshot how LLs impact relational quality but suggesting some potential problems with the concept of LLs.

For first two research questions about the forced-choice option as compared with the 20 -item LLS, results indicated no significant differences. People's forced-choice preferred LL did not surface as a single preferred LL on the 20 -item LLS. The same held true with regard to each partner's forced-choice preferred LL and the 20-item LLS for what partner's reported tending to give - no significant differences surfaced. The lack of significant findings suggests further testing should be conducted before making any generalizations about LLs. Whereas, it might be easy simply to say that the LLS did not accurately predict a person's preferred LL, we suggest other reasons should be considered. The main reason we contend that the scale itself is valid relates to the CFA results for the LLS. The data fit the models well, or at acceptable levels, especially considering the sample size. For example one reason the LLS scale did not accurately predict a person's preferred LL may relate to the age of participants. Young romantic couples may struggle, for example, about how much touch, especially sexual touch, should define the relationship. This might indicate that people need a period of time after entering adulthood before they experience that immediate LL recognition that Chapman (1992) discussed. Perhaps instead, at that relational stage, young couples feel that all the LL behaviors are important. This also would support Dainton's (2000) claim that people expect partners to perform all types of relational maintenance behaviors. Further testing could debunk Chapman's notion of a single LL preference and provide more support for the idea that people expect a variety of behaviors that do not fall into one particular category, or LL.

After clustering the couples into 12 types based on preferences to receive and tendencies to give LLs and then paring down those 12 types into 3 categories (match, partial match, or mismatch) in order to address the fourth question, these data revealed some important findings about the nature of LLs and how they support Chapman's (1992) claims. Of 
Table 3. One-Way ANOVAs Comparing Partners' Forced-Choice Feel Love Language with Their Partners' Tendency to Give Love Language Scale Subscores

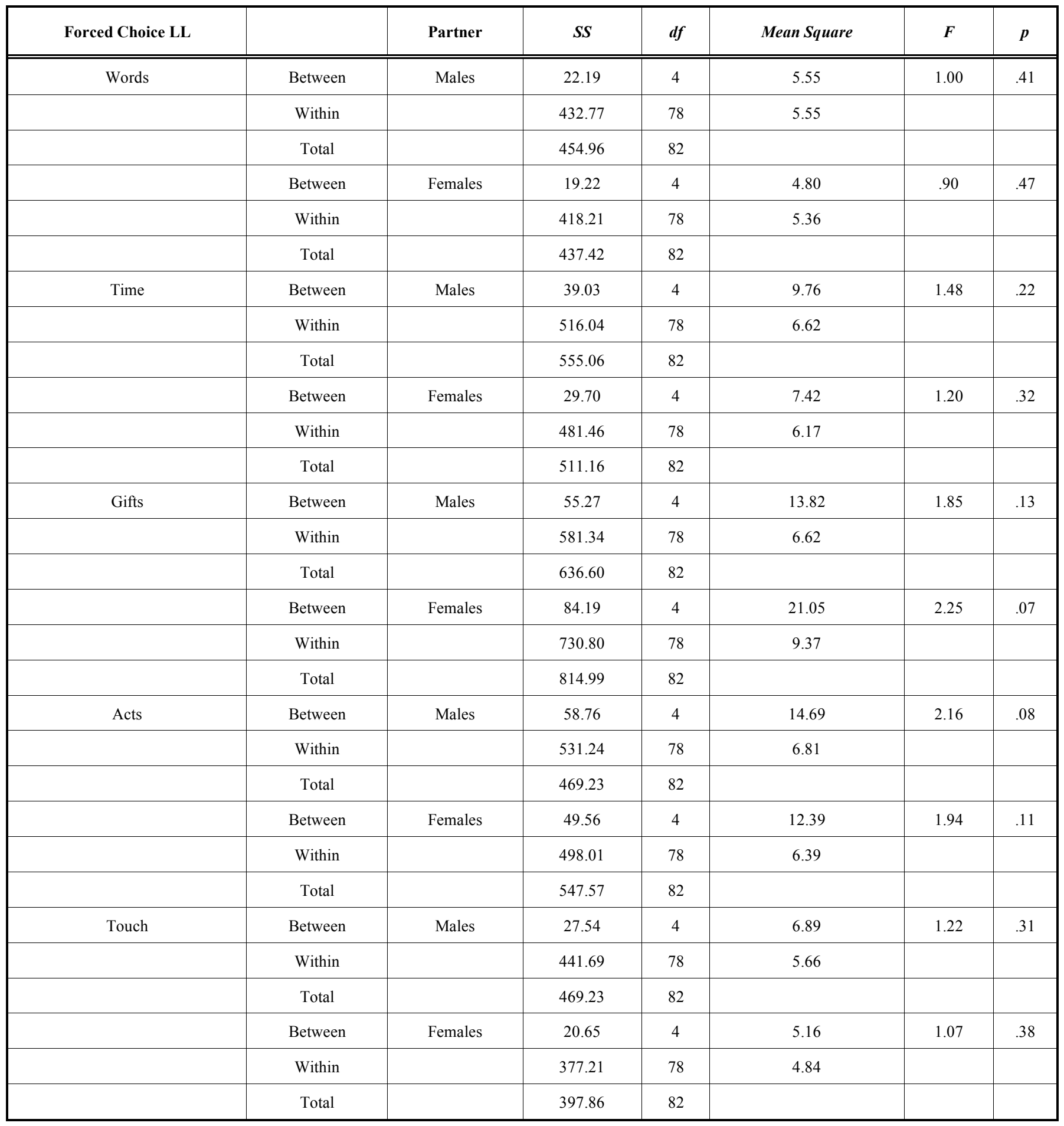

the 83 couples, 22 represent a matching type, 13 represent a partial match, and 48 represent a match. These findings suggest Chapman was onto something about partners often not giving one another's preferred LL. Given the large number of mismatches (partial or total) -- a full 73.5\% of the couples experienced a partial or total mismatch as compared with $26.5 \%$ matches - this result points to the possibility that mismatches could be important to understanding relational outcomes, and especially that mismatches may negatively affect relational quality.

Some of the specific findings about the 12 couple types also are worth discussion. None of the 83 couples matched the style that Chapman (1992) advocated (needing to learn to express a partner's LL). Of the 22 matched couples, none of them actually had to alter their behavior to match their partner's LL - it already matched their own. This finding is 
important because couples might not be adapting to a partner's LL preference, or it is an infrequent occurrence (under $1.2 \%$ of couples in this study). The couples that reported a match were couples where both partners felt and gave the same LL, suggesting that making a conscious choice to "speak" a partner's LL may not apply to the couples in this study.

Table 4. Means and Standard Deviations from Mixed-Model MANOVA Comparing Partners' Forced-Choice Feel Love Language with Their Partners' Tendency to Give Love Language Scale Subscores

\begin{tabular}{|c|c|c|}
\hline LL Item & Mean & SD \\
\hline \hline Words & 17.46 & 2.27 \\
\hline Time & 17.67 & 2.31 \\
\hline Gifts & 15.62 & 3.29 \\
\hline Acts & 16.02 & 2.87 \\
\hline Touch & 18.25 & 2.07 \\
\hline
\end{tabular}

Because Chapman (1992) claimed that mismatches often occur, noting the types of mismatch is worthwhile. Of mismatched couples, the most frequent and most obvious finding is that when partners feel different LLs, they are likely to give what they feel. Our sample included 39 mismatched couples who reported this, and an additional 13 couples reported a partial match, meaning that only one partner is having his/her love tank filled. This suggests Chapman is correct in attempting to help people understand the impact of LL differences, and all of these couple types are candidates for Chapman's message.

Perhaps the most interesting couples are the five couple types $(5,6,7,8$, and 9 ; see Table 5) who represented the other types of mismatches. For example, in couple type 5, both partners actually prefer the same LL, but neither partner gives this preferred LL. These partners contradict Chapman's (1992) idea that people give their own preferred LL. In addition, in couple 7, each partner feels a different LL and gives a LL different from their preference, but it still does not match each partner's preference. In addition, couples 6 and 8 are interesting because they represent a complex type of couple where one partner gives the LL that $\mathrm{s} /$ he feels (which Chapman claims is natural), and the other partner gives a LL different from his/her own preference; however, both partners fail to give the other's preference. Luckily, no couples reported the type 9 mismatch where couples each prefer a different LL from one another; yet, they give a LL different both from their own and from their partner's preference.

In these mismatched cases, additional variables could explain the LL discrepancies. First, partners see themselves as complementary in terms of LL, suggesting they do not expect the other partner desires the same type of behaviors. Another explanation is, like Stafford and Canary (1991) found, the type of relationship (dating, dating seriously, engaged, married) could factor into reports of relational behaviors that are similar to LLs. Finally, maybe like Bell,
Daly, and Gonzalez (1987) found, perception of quantity of behaviors is less important than the type of LL performed.

These data revealed that matched and mismatched couples reported greater consistency in their individual-level assessments of relational quality than partially matched couples. No difference between mismatched and matched couples arose, but both were different from partially matched couples. Equity theory provides some support (Walster, Walster, \& Berscheid, 1978); if both partners perceive similar needs (either being met or unmet) they may perceive equity. Although not ideal, this situation may be more satisfactory than when one partner feels underbenefited whereas the other is receiving what $\mathrm{s} /$ he desires. For example, Sprecher (2001) found underbenefiting, but not overbenefiting, is significantly associated with distress, and being underbenefited may motivate people to demand equity (Hatfield \& Rason, 1995). Such demands may play out differently depending on whether one or both partners feel underbenefited about LLs.

In addition, Dainton (2003) found inequity was linked positively with the relational maintenance behavior of openness and suggested that people may use openness as an equity restoration behavior. Furthermore, researchers have linked sexual behaviors (initiating, agreeing to, or refusing sex) with inequity. Perhaps this means that people change the LL they give after perceiving inequity in terms of what they receive - not to punish the partner by discontinuing his/her felt LL - but by attempting to alert their partner of perceived inequity.

The lack of significance for the final research question may be the result of the effects being washed out by the combined total scores. The crosstabs analysis results seem puzzling. Namely, the couples with mismatched LLs largely reported high relational quality. Perhaps again, as long as both partners feel underbenefited, they may not experience diminished relational quality.

\section{LIMITATIONS AND FUTURE DIRECTIONS}

One limitation to this study is its homogenous college student sample. Although this population is socially active and invested in romantic relationships, the relationships tend to be less developed than in the general population. In addition, by virtue of age, many of them tend to be less experienced in relationships. More diversity of participants also would make the results more generalizable. Having a sample that includes couples with a wide scope of relationship length would help us to verify the extent to which the LLS accurately measures Chapman's notion of a single favorite LL.

Variables like relationship length and age affect relational behaviors over time. For example, maintenance changes over the course of relationships (Stafford \& Canary, 1991; Canary, Stafford, \& Semic (2002). In addition, Ciak, Hutchison, Reed, and Saner (2009) found that time impacted people's attributions of flirting behaviors, Willis and Briggs (1992) found gender differences in the initiation of touch among dating or married couples, and Guerrero and Anderson (1994) found that partners increasingly matched touch behavior as the relationship developed. Therefore, it is worthwhile to test the extent to which people's felt LL 
Table 5. Different Love Language Couple Combinations

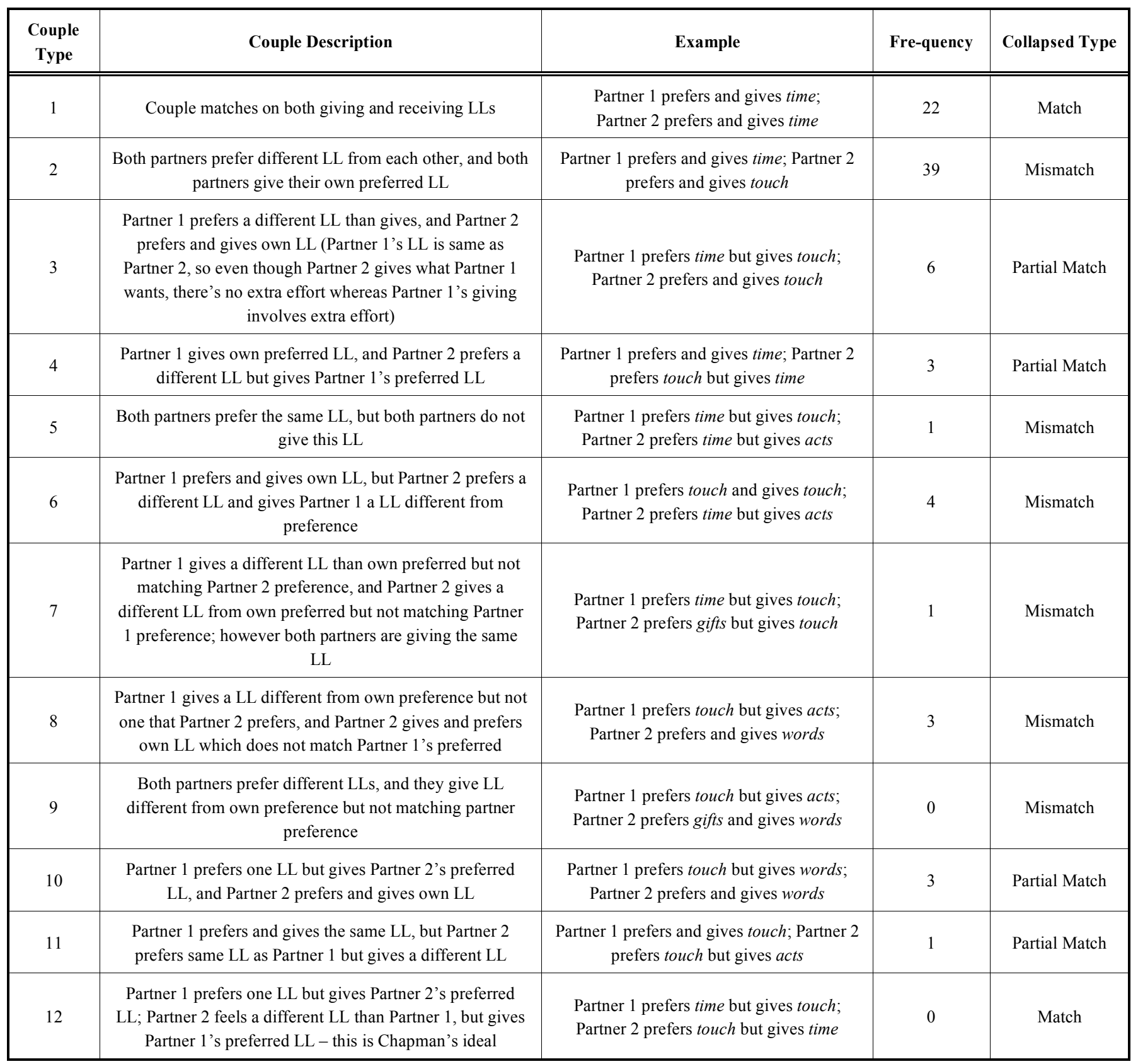

Note: The examples do not represent all the LL combinations possible within that couple type

changes rather than being trait-like as Chapman (1992) suggests.

Future studies also could look at more complex combinations of data. In addition to collecting data on selfreports of LL preferences and partner reports of giving LLs, it would be helpful to gather data on what LL behaviors people perceive their partners give them. Dindia (2000) suggested that research should explore the relationship between perceptions of partner behaviors, satisfaction, and the amount and type of enacted behaviors. Chapman's (1992) theory provides a relevant link to this needed research because of his clear claims about learning to enact a partner's felt LL rather than simply to enact those preferred by oneself. Perhaps specific LL combinations lead to higher relational quality. For example, perhaps couples in which both partners prefer and give time report higher relational quality than couples in which both partners prefer and give acts.

\section{CONCLUSION}

We hope this research stimulates more study of relational behaviors and relational quality. Of special note is the finding that behavioral discrepancies offer more explanatory power than the behaviors themselves. The most pressing issue is determining the nature of discrepancies between partners' desires and what the other gives. Are these discrepancies relationship-promoting or the cause for unmet expectations and disappointment? Whereas this study 
Table 6. Frequency of Collapsed Couple Relational Quality by Collapsed Couple Type

\begin{tabular}{|c|c|c|c|c|}
\hline $\begin{array}{c}\text { Collapsed Couple } \\
\text { Type }\end{array}$ & $\begin{array}{c}\text { Represented by Couple } \\
\text { Types }\end{array}$ & $\begin{array}{c}\text { Matching High Relational } \\
\text { Quality }\end{array}$ & $\begin{array}{c}\text { Matching Low Relational } \\
\text { Quality }\end{array}$ & $\begin{array}{c}\text { Mismatched Relational } \\
\text { Quality }\end{array}$ \\
\hline \hline Match & $1 \& 12$ & 14 & 2 & 6 \\
\hline Partial Match & $3,4,10, \& 11$ & 6 & 1 & 6 \\
\hline Mismatch & $2,5,6,7,8, \& 9$ & 28 & 6 & 14 \\
\hline
\end{tabular}

Table 7. Crosstabs Analysis of Collapsed Couple Relational Quality and Collapsed Couple Type

\begin{tabular}{|c|c|c|c|c|}
\hline \multicolumn{5}{|l|}{ Count } \\
\hline \multirow[b]{2}{*}{ Coll Type } & Match & 16 & 6 & 22 \\
\hline & Partial & 7 & 6 & 13 \\
\hline \multicolumn{2}{|c|}{ Total } & 56 & 27 & 83 \\
\hline
\end{tabular}

pointed out the importance of this issue and the possible configurations of such discrepancies in couples, only future research can provide the explanations.

\section{CONFLICT OF INTEREST}

The authors confirm that this article content has no conflicts of interest.

\section{ACKNOWLEDGEMENTS}

The authors wish to thank Mary E. Braz for the consultation she provided on this project.

\section{REFERENCES}

Bell, R. A., Daly, J. A., \& Gonzalez, M. C. (1987). Affinity-maintenance in marriage and its relationship to women's marital satisfaction. Journal of Marriage and Family, 49, 445-454.

Bell, R. A., \& Healey, J. G. (1992). Idiomatic communication and interpersonal solidarity in friends' relational cultures. Human Communication Research, 18, 307-355.

Bollen, K. A. (1989). Structural equations with latent variables. New York: John Wiley \& Sons.

Browne, M. W. \& Cudeck, R. (1993). Alternative ways of assessing model fit. In: K. A. Bollen, \& J. S. Long, (Eds.) Testing structural equation models (pp. 136-162). Beverly Hills, CA: Sage

Burleson, B. R., \& Denton, W. H. (1992). A new look at similarity and attraction in marriage: Similarities in social-cognitive and communication skills as predictors of attraction and satisfaction. Communication Monographs, 59, 268-287.

Burleson, B. R., Kunkel, A. W., \& Birch, J. D. (1994). Thoughts about talk in romantic relationships: Similarity makes for attraction (and happiness too). Communication Quarterly, 42, 259-273.

Burgoon, J. K. (1978). A communication model of personal space violations: Explication and an initial test. Human Communication Research, 4, 129-142.

Burgoon, J. K., Dillman, L., \& Stern, L. A. (1993). Adaptation in dyadic interaction: Defining and operationalize patterns of reciprocity and compensation. Communication Theory, 4, 293-316.

Canary, D. J., Stafford, L., \& Semic, B. A. (2002). A panel study of the associations between maintenance strategies and relational characteristics. Journal of Marriage and the Family, 64, 395-406.
Carmines, E. G., \& McIver, J. P. (1981). Analyzing models with unobserved variables : Analysis of covariance structures. In G. W. Bohrnstedt and E. F. Borgatta, (Eds.), Social measurement: Current issues (pp. 65-115). Beverly Hills, CA : Sage.

Cassidy, J., \& Shaver, P. R. (Eds.) (2008). Handbook of attachment: Theory, research and clinical applications $\left(2^{\text {nd }} e d.\right)$. New York: Guilford.

Chapman, G. (1992). The five love languages: How to express heartfelt commitment to your mate. Chicago, IL: Northfield Publishing.

Ciak, G., Hutchison, E., Reed, K., \& Saner, J. (2009). Same flirting, different meaning: A study of flirting in casual and serious romantic relationships. Paper presented at the meeting of the National Communication Association, Chicago.

Cutrona, C. E., \& Suhr, J. A. (1990). Social support and becoming a parent. In S. Fisher \& T. Cooper (Eds.), On the move: The psychological effects of change and transition (pp. 111-125). New York: Wiley.

Cutrona, C. E., \& Suhr, J. A. (1992). Controllability of stressful events and satisfaction with spouse support behaviors. Communication Research, 19, 154-174.

Dainton, M. (2000). Maintenance behaviors, expectations for maintenance, and satisfaction: Linking comparison levels to relational maintenance strategies. Journal of Social and Personal Relationships, 17, 827-842.

Dainton, M. (2003). Equity and uncertainty in relational maintenance. Western Journal of Communication, 67, 164-186.

Dindia, K. (2000). Relational maintenance. In C. Hendrick \& S. S. Hendrick (Eds.), Close relationships: A sourcebook (pp. 287-299). Thousand Oaks, CA: Sage.

Downs, V. C., \& Javidi, M. (1990). Linking communication motives to loneliness in the lives of older adults: An empirical test of interpersonal needs and gratifications. Journal of Applied Communication Research, 18, 32-48.

Egbert, N., \& Polk, D. (2006). Speaking the language of relational maintenance: A validity test of Chapman's (1992) five love languages. Communication Research Reports, 23, 1-8.

Feeney, J. A. (2008). Adult romantic attachment: Developments in the study of couple relationships. In J. Cassidy \& P. R. Shaver (Eds.), Handbook of Attachment: Theory, Research, and Clinical Applications (pp. 456-481). New York: Guilford.

Floyd, K. (2001). Human affection exchange: I. Reproductive probability as a predictor of men's affection with their sons. Journal of Men's Studies, 10, 39-50.

Floyd, K. (2003). Human affection exchange: V. Attributes of the highly affectionate. Communication Quarterly, 50, 135-152. 
Floyd, K. (2006). Communicating affection: Interpersonal behavior and social context. New York: Cambridge University Press.

Floyd, K., \& Burgoon, J. K. (1999). Reacting to nonverbal expressions of liking: A test of interaction adaptation theory. Communication Monographs, 66, 219-239.

Floyd, K., Hesse, C., \& Haynes, M. T. (2007). Human affection exchange: $\mathrm{XV}$. Metabolic and cardiovascular correlates of trait expressed affection. Communication Quarterly, 55, 79-94.

Floyd, K., Hess, J. A., Miczo, L. A., Halone, K. K., Mikkelson, A. C., \& Tusing, K. J. (2005). Human affection exchange: VIII. Further evidence of the benefits of expressed affection. Communication Quarterly, 53, 285-303.

Floyd, K., \& Morman, M. T. (1998). The measurement of affectionate communication. Communication Quarterly, 46, 144-162.

Floyd, K., \& Morman, M. T. (2003). Human affection exchange: II. Affectionate communication in father-son relationships. Journal of Social Psychology, 143, 599-612.

Fuller, T. L., \& Fincham, F. D. (1995). Attachment style in married couples: Relation to current marital functioning, stability over time, and method of assessment. Personal Relationships, 2, 17-34.

Hatfield, E., \& Rason, R. L. (1995). A world of passion: Cross-cultural perspectives on love and sex. New York: Allyn \& Bacon.

Hazan, C., \& Shaver, P. (1987). Romantic love conceptualized as an attachment process. Journal of Personality and Social Psychology, 52, 511-524

Hazan, C., \& Shaver, P. (1994). Attachment as an organizational framework for research on close relationships. Psychological Inquiry, 5, 1-22.

Hu, L. T. \& Bentler, P. M. (1999). Cutoff criteria for fit indexes in covariance structure analysis: Conventional criteria versus new alternatives. Structural Equation Modeling, 6(1), 1-55.

Guerrero, L. K., \& Anderson, P. A. (1994). Patterns of matching and initiation: Touch behavior and touch avoidance across romantic relationship stages. Journal of Nonverbal Behavior, 18, 137-153.

Johnson, A. J. (2001) Examining the maintenance of friendships: Are there differences between geographically close and long-distance friendships? Communication Quarterly, 49, 424-435.

Kenny, D. A. \& McCoach, D. B. (2003). Effect of the number of variables on measures of fit in structural equation modeling. Structural Equation Modeling, 10(3), 333-51.

Leverett, J. E. (2007). Relational maintenance behaviors between college freshmen and their parents via instant messaging. Master's thesis. Retrieved from Proquest on April 18, 2012, from http://search.proquest.com/docview/304713105 Publication number 1442586.

MacCallum, R. C., Browne, M. W., \& Sugawara, H. M. (1996). Power analysis and determination of sample size for covariance structure modeling. Psychological Methods, 1(2), 130-49.
Marriage \& Family Life Consultants (n.d.) Biography. Retrieved on August 19, 2011, from http://www.garychapman.org/bio.htm.

Meyers, S. A., \& Landsberger, S. A. (2002). Direct and indirect pathways between adult attachment style and marital satisfaction. Personal Relationships, 9, 159-171.

Miles, J. \& Shevlin, M. (1998). Effects of sample size, model specification and factor loadings on the GFI in confirmatory factor analysis. Personality and Individual Differences, 25, 85-90.

Mueller, R. O. (1996). Basic principles of structural equation modeling. New York: Springer-Verlag.

Pierce, G. R. (1994). The quality of relationships inventory: Assessing the interpersonal context of social support. In B. Burleson, T. Albrecht, \& I. Sarason (Eds.) Communication of social support: Messages, interactions, relationships, and community (pp. 247-266). Thousand Oaks, CA: Sage.

Rusbult, C. E., Olsen, N., Davis, J. L., \& Hannon, P. (2001). Commitment and relationship maintenance mechanisms. In J. H. Harvey \& A. Wenzel (Eds.), Close romantic relationships: Maintenance and enhancement (pp. 87-113). Mahwah, NJ: Erlbaum.

Schutz, W. (1958). FIRO: A three-dimensional theory of interpersonal behavior. New York: Rinehart.

Schrodt, P., Ledbetter, A. M., \& Ohrt, J. K. (2007). Parental confirmation and affection as mediators of family communication patterns and children's mental well-being. Journal of Family Communication, 7, 23-46.

Sprecher, S. (2001). Equity and social exchange in dating couples: Association with satisfaction, commitment, and stability. Journal of Marriage and Family, 63, 599-613.

Stafford, L., \& Canary, D. J. (1991). Maintenance strategies and romantic relationship type, gender, and relational characteristics. Journal of Social and Personal Relationships, 8, 217-242.

Thibaut, J. W., \& Kelley, H. H. (1959). The Social Psychology of Groups. New York: John Wiley.

Verhofstadt, L. L., Buysse, A., Rosseel, Y. \& Peene, O. J. (2006) Confirming the three-factor structure of the quality of relationships inventory within couples. Psychological Assessment, 18, 15-21.

Villard, K., \& Whipple, L. (1976). Beginnings in relational communication (pp. 141-165). New York: John Wiley.

Walster, E., Walster, G. W., \& Bershcheid, E. (1987). Equity: Theory and research. New York: Allyn and Bacon, Inc.

Weger, H., \& Polcar, L. E. (2000). Attachment style and the cognitive representation of communication situations. Communication Studies, 51, 149-161.

Wheaton, B., Muthen, B., Alwin, D., F., \& Summers, G. (1977). Assessing reliability and stability in panel models, Sociological Methodology, $8(1), 84-136$.

Willis, F, N., \& Briggs, L .F. (1992). Relationship and touch in pubic settings. Journal of Nonverbal Behavior, 16, 55-63.

Received: September 20, 2012

Revised: March 19, 2013

Accepted: March 22, 2013

(C) Polk and Egbert; Licensee Bentham Open.

This is an open access article licensed under the terms of the Creative Commons Attribution Non-Commercial License (http://creativecommons.org/licenses/by-nc/3.0/) which permits unrestricted, non-commercial use, distribution and reproduction in any medium, provided the work is properly cited. 